\title{
Gold immunochromatographic assay for simultaneous detection of sibutramine and sildenafil in slimming tea and coffee
}

\author{
Steven Suryoprabowo ${ }^{1,2}$, Liqiang Liu ${ }^{1,2}$, Hua Kuang ${ }^{1,2}$, Gang Cui ${ }^{3}$ and Chuanlai $\mathrm{Xu}^{1,2^{*}}$
}

Weight gain and obesity are worldwide problems prompting a search for many health supplements that provide benefits such as revitalization, skin-beautification, visual improvement, and slimming effects, mainly based on herbal formulations as an alternative treatment. Obesity may be defined as decreased physical activity, energy intake greater than energy expenditure, poor eating habits, neurogenic abnormalities, and genetic factors that have negative impact on the quality of life [1-3]. Sibutramine (SB) is one of the most widely used herbal formulations or dietary supplements used for weight loss. It has also been used to treat polycystic ovary syndrome, and usually found in anorexic drugs used in herbal slimming [4-6]. Sildenafil (SID) is a phosphodiesterase inhibitor and commonly used for erectile dysfunction treatment. It acts by blocking phosphodiesterase 5 (an enzyme that promotes the breakdown of cyclic guanosine monophosphate), which increases blood flow. Common side effects of SID include headaches, heartburn and flushed skin [7-9]. The use of SB and SID as additives in commercial foods and their unregulated intake are illegal and can affect human health and even threaten the lives of consumers [10,11]. Therefore, an effective and rapid method for detection of them is needed to guarantee the quality of functional foods and to protect consumers effectively.

Several techniques have been used to detect SB and SID such as gas chromatography [12-15], high performance liquid chromatography [16-18], and liquid chromatography-tandem mass chromatography [19-22]. Critically, these methods need time and expert personnel to run the analyses, require cleaning procedures, and they are of low sensitivity and expensive. Furthermore, these methods do not meet current legislative requirements [23-26]. Alternatively, immunoassays are popularly used because they have high sensitivity and specificity, and are less time-consuming and inexpensive. The determination of SID in functional food using an enzyme-linked immunosorbent assay (ELISA) has been developed [27], which is useful for the analysis of multiple samples. Even though ELISAs have high sensitivity, specificity, ease of use and low cost, they require long incubation times and multiple steps for the enzyme reactions, which are unsuitable for on-site detection [28-31].

The recently developed immunochromatographic or lateral flow immunoassay (LFIA) test strips are popular for detecting various analytes, including drugs, pesticides, toxins, and antibiotics [32-34]. LFIA tests are performed by spraying all reagents onto the strips, and thus they are easy to use, sensitive, specific and rapid, which represent a major advantage over other methods (results can be seen within 5-10 $\mathrm{min}$ ) $[35,36]$. To our knowledge, no LFIA has been developed to determine $\mathrm{SB}$, though it is currently used for rapid screening of SID in functional foods [37]. In this study, we aim to develop an LFIA to simultaneously determine SB and SID in slimming tea and coffee.

For the LFIA, gold nanoparticles (AuNPs) were firstly prepared, and then combined with monoclonal antibody $(\mathrm{mAb})$. Briefly, a solution of $\mathrm{HAuCl}_{4}\left(10 \mathrm{mmol} \mathrm{L}^{-1}\right.$, $12.5 \mathrm{~mL})$ made with ultrapure water $(487.5 \mathrm{~mL}$, filtered through a membrane $0.22 \mu \mathrm{m}$ ) was boiled and constantly stirred for $15 \mathrm{~min}$. Then, $1 \mathrm{~mL}$ of sodium citrate tribasic dihydrate $(10 \%, w / v)$ was added and stirred until a red-

\footnotetext{
${ }^{1}$ State Key Laboratory of Food Science and Technology, Jiangnan University, Wuxi 214122, China

${ }^{2}$ International Joint Research Laboratory for Biointerface and Biodetection, and School of Food Science and Technology, Jiangnan University, Wuxi 214122, China

${ }^{3}$ School of Life Sciences, Yancheng Teachers University, Yancheng 224002, China

* Corresponding author (email: xcl@jiangnan.edu.cn)
} 
wine color developed (after $30 \mathrm{~min}$ ). After this, the solution was cooled to room temperature, and the obtained AuNPs (Fig. 1) were stored at $4^{\circ} \mathrm{C}$ before antibody labeling. Purified anti-SB and anti-SID mAbs were produced by our laboratory, and used for the preparation of the colloidal gold (CG)-labelled mAbs. Briefly, a certain amount of $\mathrm{K}_{2} \mathrm{CO}_{3}\left(0.1 \mathrm{~mol} \mathrm{~L}^{-1}\right)$ was added into the CG solution $(10 \mathrm{~mL})$ to adjust the $\mathrm{pH}$ to 7.0 . Then, $0.4 \mathrm{~mL}$ of purified $\mathrm{mAb}$, adjusted to $0.2 \mathrm{mg} \mathrm{mL}^{-1}$ with borate buffer $\left(0.02 \mathrm{~mol} \mathrm{~L}^{-1}\right)$, was added to the $\mathrm{CG}$, and the mixture left for $35 \mathrm{~min}$ at room temperature. Free CG was blocked with $1 \mathrm{~mL}$ of $10 \%(w / v)$ bovine serum albumin (BSA) for $2 \mathrm{~h}$ at room temperature. After the blocking step, the solution was centrifuged for $45 \mathrm{~min}$ at $6266 \times \mathrm{g}$ at $4^{\circ} \mathrm{C}$ to remove the unconjugated antibody. After centrifugation, the supernatant was removed, and $1 \mathrm{~mL}$ of resuspension buffer $\left(0.02 \mathrm{~mol} \mathrm{~L}^{-1}\right.$ Tris-HCl, $\quad 0.1 \%$ Tween-20, $0.1 \%$ poly(ethylene glycol) (PEG), 1\% polyvinylpyrrolidone (PVP), $5 \%$ sucrose, $4 \%$ trehalose, $2 \%$ sorbitol, $1 \%$ mannitol, $0.04 \% \mathrm{NaN}_{3}$, and $0.2 \% \mathrm{BSA}$ ) was added. The suspension of CG-mAb conjugate was stored at $4^{\circ} \mathrm{C}$.

A schematic representation of the assay is shown in Fig. 2, including the capture and control reagents used to spray onto the nitrocellulose (NC) membrane, plastic backing plate (polyvinyl chloride, PVC), conjugate pad with CG-mAb, sample pad, and absorbent pad (all pasted onto a plate). The coating antigen hapten-SID-BSA (test line 1, T1), hapten-SB-OVA (test line 2, T2) and the

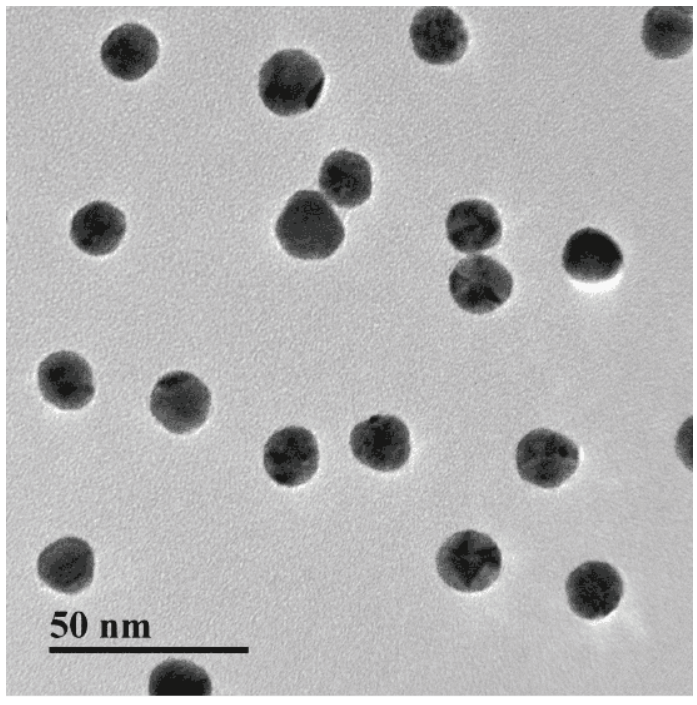

Figure 1 Characterization of colloidal AuNPs ( $15 \mathrm{~nm}$ ) by using transmission electron microscopy.

control line ( $\mathrm{C}$, goat anti-mouse $\mathrm{IgG}$ antibody) were sprayed onto the NC membrane $\left(0.9 \mu \mathrm{L} \mathrm{cm}^{-1}\right)$, representing the two test lines and the control. After being sprayed onto the NC membrane, the capture and control reagents were dried at $37^{\circ} \mathrm{C}$ overnight. Then the plate was cut into narrow strips $(2.9 \mathrm{~mm}$ wide) by using a strip cutter.

Due to the stability and the charge of the conjugation,

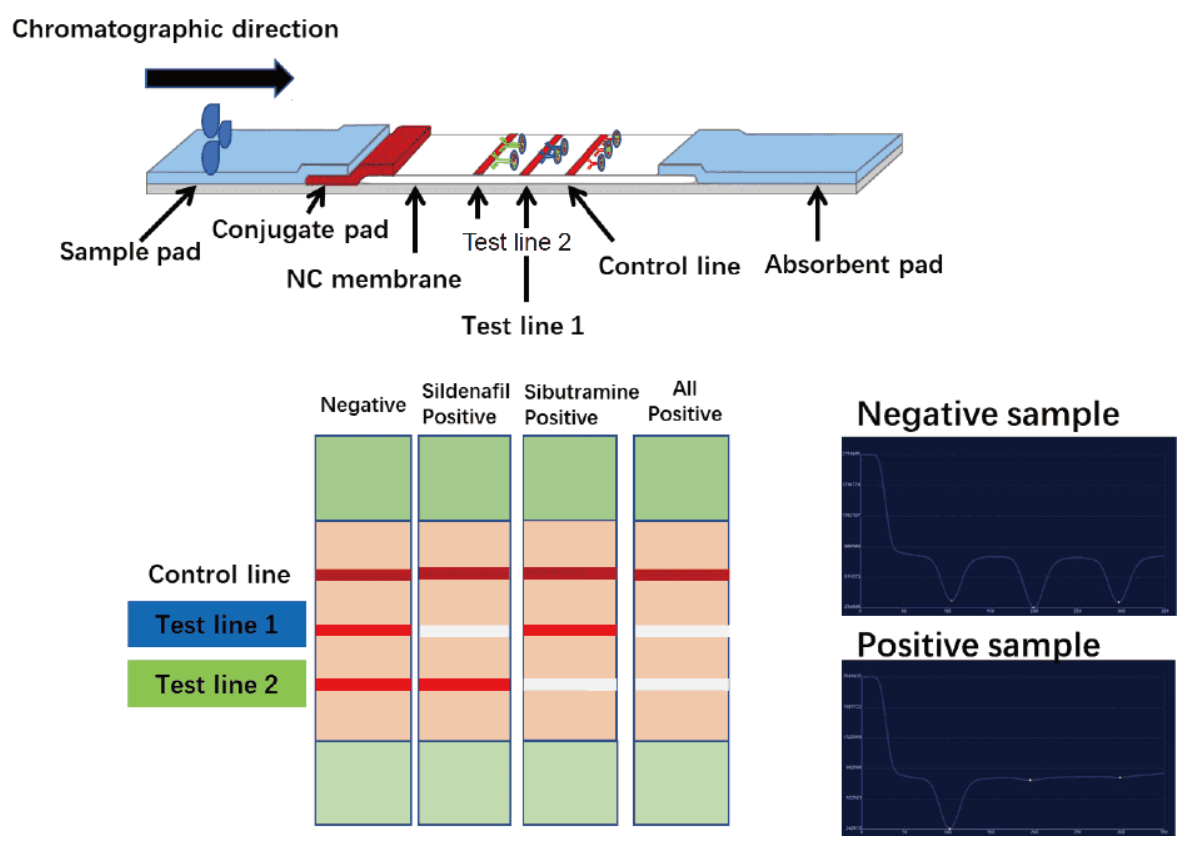

Figure 2 Schematic and illustration of typical strip test results. 
the $\mathrm{pH}$ may affect its performance. In this study, BSA $(10 \%, 1 \mathrm{~mL})$ was used to stabilize the CG-antibody conjugate and reduce the nonspecific background. The experimental condition, including concentration of each antibody (8 and $10 \mu \mathrm{g} \mathrm{mL}^{-1}$ ) and amount of $\mathrm{K}_{2} \mathrm{CO}_{3}(4$ and $8 \mu \mathrm{L} \mathrm{mL}^{-1}$ added in the AuNP solution), was optimized. After optimization, $\mathrm{K}_{2} \mathrm{CO}_{3}\left(0.1 \mathrm{~mol} \mathrm{~L}^{-1}, 4 \mu \mathrm{L} \mathrm{mL}^{-1}\right.$ added) and $8 \mu \mathrm{g} \mathrm{mL}^{-1}$ of the concentrated antibody were used for further experiments. While developing this assay, choosing the appropriate surfactant was very important because of incompatibility issues between the surfactant and protein. In this study, the mAb-AuNPs were diluted five times with the suspension buffer $\left(0.02 \mathrm{~mol} \mathrm{~L}^{-1}\right.$ Tris$\mathrm{HCl}, 500 \mathrm{~mL}$ ) containing $5 \%$ sucrose, $0.1 \%$ PEG, $0.1 \%$ Tween-20, 5\% trehalose, and $0.2 \%$ BSA, mixed with six different types of reagents: Tween-20, PVP, PEG, BSA, Brij-30, and ON-870 (each concentration was 5\%), respectively, and sprayed onto the conjugate pad. After optimization, based on the color intensity at $0 \mathrm{ng} \mathrm{mL}^{-1}$ (control) and cut-off (500 $\mathrm{ng} \mathrm{mL}^{-1}$ ) using phosphate buffer saline (PBS, $0.01 \mathrm{~mol} \mathrm{~L}^{-1}, \mathrm{pH}$ 7.4) (Fig. 3a), the most stable and intense deep red color on the test line was seen by using the surfactant ON-870. Different concentrations of the two analytes were mixed with PBS $\left(0.01 \mathrm{~mol} \mathrm{~L}^{-1}, \mathrm{pH} 7.4\right)$. Fig. 3b shows that a negative sample $\left(0 \mathrm{ng} \mathrm{mL}^{-1}\right)$ had a deep color and the color be-
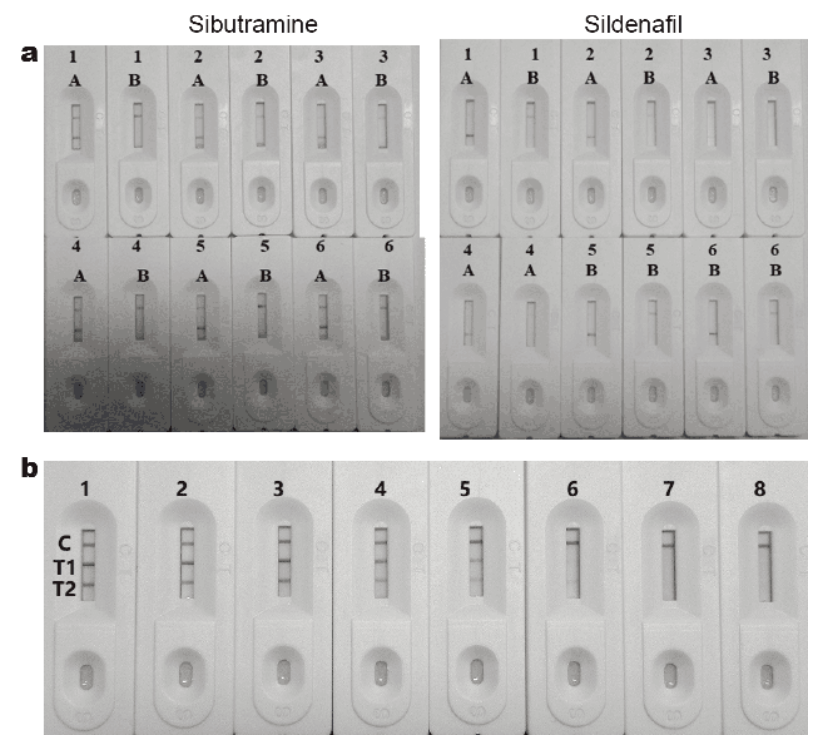

Figure 3 (a) Optimization of the experimental condition: results using six kinds of reagents for SB and SID. 1, Tween-20; 2, PVP; 3, PEG; 4, BSA; 5, Brij-30; and 6, ON-870, detected by using $0.01 \mathrm{~mol} \mathrm{~L}^{-1} \mathrm{PBS}(\mathrm{pH}$ 7.4) with $0 \mathrm{ng} \mathrm{mL}^{-1}$ (A) and $500 \mathrm{ng} \mathrm{mL}^{-1}$ (B). (b) LFIA for detection of the two analytes in $0.01 \mathrm{~mol} \mathrm{~L}^{-1} \mathrm{PBS}(\mathrm{pH}$ 7.4). (1-8) represent concentrations of $0,10,25,50,100,250,500$ and $1000 \mathrm{ng} \mathrm{mL}^{-1}$. C, control line; T1, SID; and T2, SB. came weaker when a higher concentration of analyte was added, and completely disappeared at $500 \mathrm{ng} \mathrm{mL}^{-1}$ of SB and SID.

The sensitivity and specificity of the LFIA were evaluated by determining each analyte separately, to ensure no interaction between the two. The results, shown in Fig. 4, demonstrate that there is no interference between the anti-SB and anti-SD, suggesting that the coating antigen is specific. The difference in structure between the two analytes is the reason for the absence of interference. This LFIA could also be used as a multi-component strip because of its efficiency and capability of determining two different kinds of analytes.

Three types of slimming tea and three types of coffee (free from SB and SID) were obtained from a local market. Approximately $1 \mathrm{~g}$ of the sample was added into a 15-mL polypropylene centrifuge tube containing $5 \mathrm{~mL}$ of ethanol, and vortexed for $10 \mathrm{~min}$. Then, the sample was treated by ultrasound in an ultrasonic bath for $20 \mathrm{~min}$. It was then centrifuged at $6226 \times \mathrm{g}$ for $10 \mathrm{~min}$ at room temperature, and the supernatant was filtered through a $0.22-\mu \mathrm{m}$ polytetrafluoroethylene membrane. Finally, the supernatant $(1 \mathrm{~mL})$ was added to $1 \mathrm{~mL}$ of PBS containing $0.5 \%$ Tween-20 (PBST) and the samples were spiked with a solution of SB and SID $\left(100 \mu \mathrm{g} \mathrm{mL}^{-1}\right.$, diluted in methanol). Each concentration of the spiked sample was analyzed six times. The spiked SB and SID concentrations were 0 (control), 10, 25, 50, 100, 250, and $500 \mathrm{ng} \mathrm{mL}^{-1}$. We optimized the extraction method by using 10\%-50\% ethanol. As shown in Fig. 5a, extraction using $50 \%$ ethanol demonstrates the best color intensity

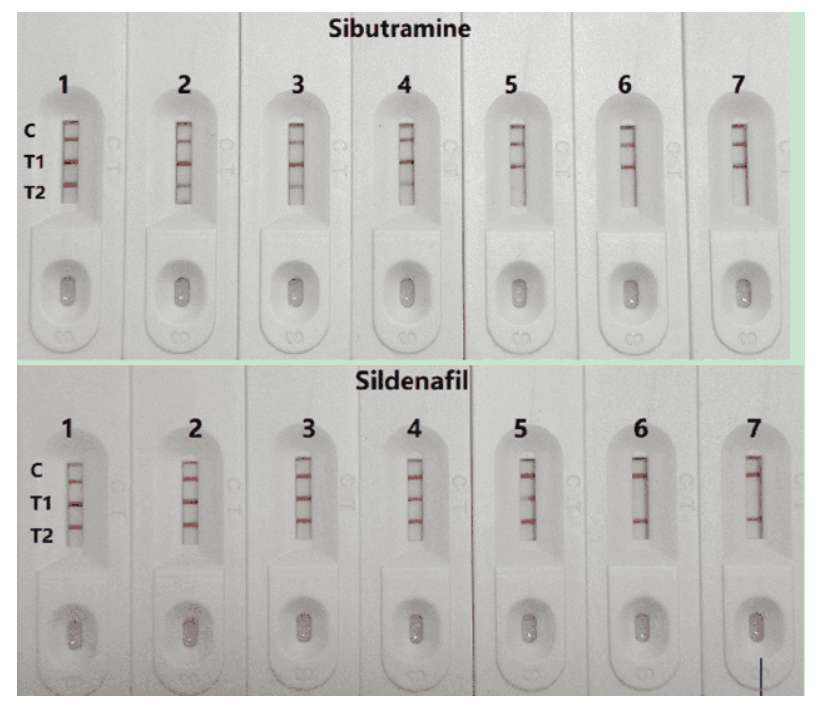

Figure 4 Typical photo images for detection of the single analyte, SB or SID. C, control line; T1, SID; and T2, SB. 

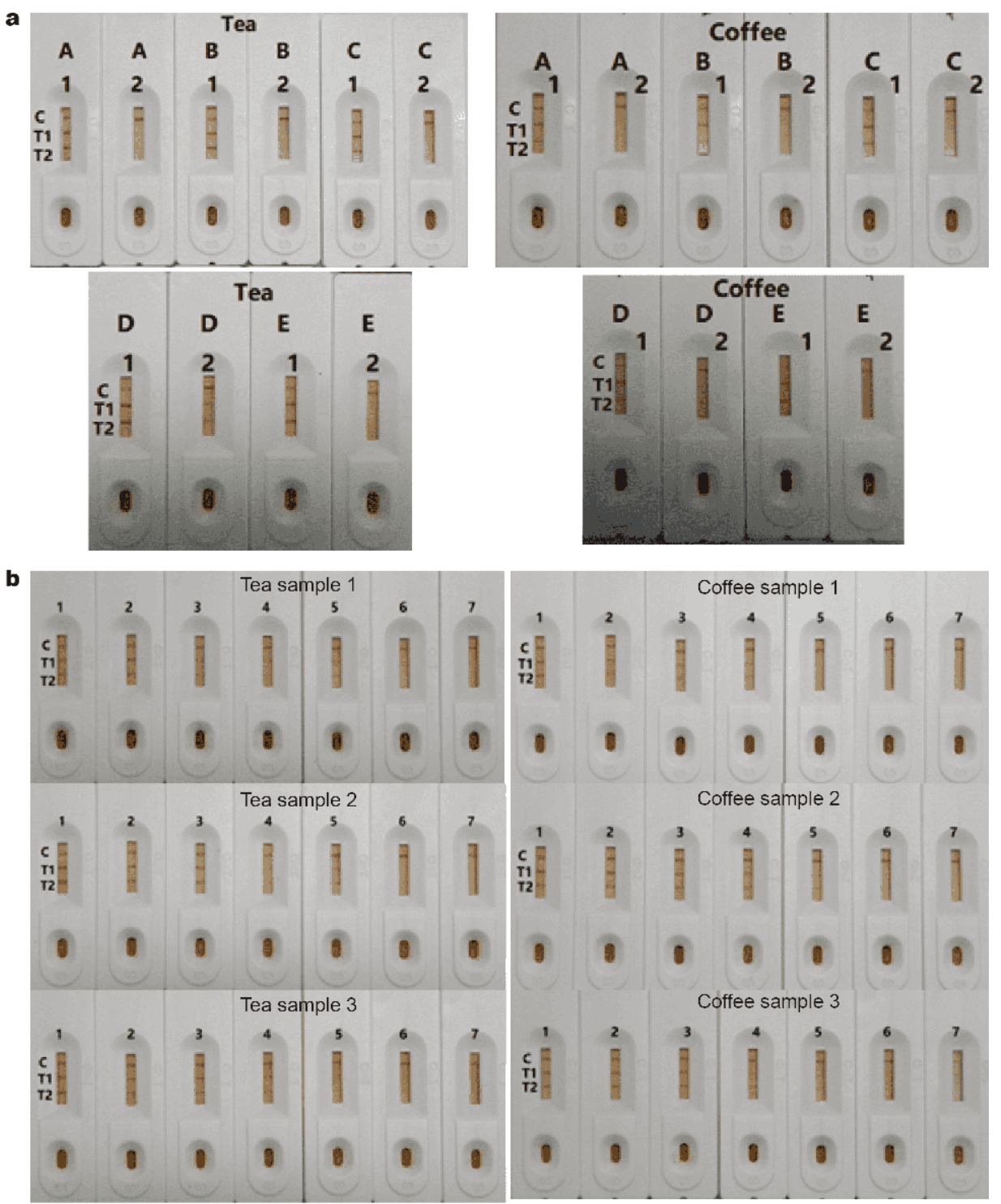

Figure 5 (a) Optimization of ethanol concentration in the extraction samples. A, 10\%; B, 20\%; C, 30\%; D, 40\%; and E, 50\%. SB and SID concentration: $1,0 \mathrm{ng} \mathrm{mL}^{-1} ; 2,500 \mathrm{ng} \mathrm{mL}^{-1}$. (b) Results for determination of analytes in the samples. (1-7) represent concentrations of $0,10,25,50,100$, 250 and $500 \mathrm{ng} \mathrm{mL}^{-1}$. C, control line; $\mathrm{T} 1, \mathrm{SID}$; and $\mathrm{T} 2, \mathrm{SB}$.

in the control and the two test lines. A standard solution of SB and SID was spiked for each sample $\left(100 \mu \mathrm{g} \mathrm{mL}^{-1}\right.$, prepared with methanol) and the final SB and SID concentrations were $10,25,50,100,250$, and $500 \mathrm{ng} \mathrm{mL}^{-1}$ (six replicates). Fig. $5 \mathrm{~b}$ shows that the color becomes weaker with increasing SB and SID concentration. Vigorous color intensity could be seen with naked eye on the test line when the concentration of analyte was $0 \mathrm{ng} \mathrm{mL}^{-1}$, and the color became weak when a higher concentration of analyte was added, and finally it completely dis- appeared at $500 \mathrm{ng} \mathrm{mL}^{-1}$ of SB and SID for each sample.

In summary, this study aimed to develop a sensitive LFIA for the rapid detection of two different analytes (SB and SID) that may exist simultaneously in slimming tea and coffee. Three types of slimming tea and three types of coffee were tested, and all the results were seen within $5 \mathrm{~min}$, by using semi-quantitative detection with naked eye. The cut-off value after optimization was $500 \mathrm{ng} \mathrm{mL}^{-1}$ for SB and SID in PBS $\left(0.01 \mathrm{~mol} \mathrm{~L}^{-1} ; \mathrm{pH}\right.$ 7.4). These results demonstrate the potential of LIFA as an effective 
and rapid method for simultaneous detection of multiple components in functional foods.

\section{Received 30 November 2019; accepted 3 December 2019; published online 8 January 2020}

1 Yuan R. Traditional Chinese medicine an approach to scientific proof and clinical validation. Pharmacol Therap, 2000, 86: 191-198

2 Yun J, Shin KJ, Choi J, et al. Isolation and structural characterization of a novel sibutramine analogue, chlorosipentramine, in a slimming dietary supplement, by using HPLC-PDA, LC-Q-TOF/ MS, FT-IR, and NMR. Forensic Sci Int, 2018, 286: 199-207

3 Phattanawasin P, Sotanaphun U, Sukwattanasinit T, et al. Quantitative determination of sibutramine in adulterated herbal slimming formulations by TLC-image analysis method. Forensic Sci Int, 2012, 219: 96-100

4 de Carvalho LM, Martini M, Moreira APL, et al. Presence of synthetic pharmaceuticals as adulterants in slimming phytotherapeutic formulations and their analytical determination. Forensic Sci Int, 2011, 204: 6-12

5 Müller D, Weinmann W, Hermanns-Clausen M. Chinese slimming capsules containing sibutramine sold over the internet: A case series. Deutsches Äerzteblatt International, 2009, 106: 218-222

6 Wang S, Yu J, Wan F, et al. Determination of sibutramine with a new sensor based on luminol electrochemiluminescence. J Lumin, 2011, 131: 1515-1519

7 Terrett NK, Bell AS, Brown D, et al. Sildenafil (VIAGRATM), a potent and selective inhibitor of type 5 cGMP phosphodiesterase with utility for the treatment of male erectile dysfunction. Bioorg Med Chem Lett, 1996, 6: 1819-1824

8 Ortiz RS, Mariotti KC, Schwab NV, et al. Fingerprinting of sildenafil citrate and tadalafil tablets in pharmaceutical formulations via X-ray fluorescence (XRF) spectrometry. J Pharm Biomed Anal, 2012, 58: 7-11

9 Wollein U, Schech B, Hardt J, et al. Determination and quantitation of sildenafil and its major metabolite in the breast milk of a lactating woman. J Pharm Biomed Anal, 2016, 120: 100-105

10 Man CN, Nor NM, Lajis R, et al. Identification of sildenafil, tadalafil and vardenafil by gas chromatography-mass spectrometry on short capillary column. J Chromatog A, 2011, 1218: 4788

$11 \mathrm{Li} \mathrm{Y,} \mathrm{Hu} \mathrm{J,} \mathrm{Shi} \mathrm{Y,} \mathrm{et} \mathrm{al.} \mathrm{Simultaneous} \mathrm{determination} \mathrm{of} \mathrm{seven}$ adulterants in slimming functional foods by HPLC-ESI-MS/MS. Food Anal Methods, 2011, 4: 505-516

12 Strano-Rossi S, Colamonici C, Botrè F. Detection of sibutramine administration: A gas chromatography/mass spectrometry study of the main urinary metabolites. Rapid Commun Mass Spectrom, 2007, 21: 79-88

13 Yamamoto S, Sumioka S, Fujioka M, et al. A study on detection of drugs in slimming health foods using GC-MS/MS. J Food Hyg Soc Jpn, 2011, 52: 363-369

14 Strano-Rossi S, Anzillotti L, de la Torre X, et al. A gas chromatography/mass spectrometry method for the determination of sildenafil, vardenafil and tadalafil and their metabolites in human urine. Rapid Commun Mass Spectrom, 2010, 24: 1697-1706

15 Jeong Y, Suh SI, Kim JY, et al. Simultaneous determination of sildenafil, tadalafil, and vardenafil in pharmaceutical preparations by high-temperature gas chromatography/mass spectrometry. Chromatographia, 2016, 79: 1671-1678 for detection of illegal adulterants in Fur seal ginseng pills by profiling analysis of HPLC multi-dimensional fingerprints. J Sep Sci, 2019, 42: 1509-1519

17 Mathon C, Ankli A, Reich E, et al. Screening and determination of sibutramine in adulterated herbal slimming supplements by HPTLC-UV densitometry. Food Add Contams-Part A, 2014, 31: $15-20$

18 Hemdan A, Tawakol SM. HPLC-UV chromatographic methods for detection and quantification of undeclared withdrawn synthetic medications in counterfeit herbal medicines with confirmation by HPLC-PDA and mass spectrometry. Chromatographia, 2018, 81: 777-783

19 Zeng Y, Xu Y, Kee CL, et al. Analysis of 40 weight loss compounds adulterated in health supplements by liquid chromatography quadrupole linear ion trap mass spectrometry. Drug Test Anal, 2016, 8: 351-356

20 Zhong Y, Sun C, Xiong J, et al. Simultaneous determination of eight adulterants in weight management supplements and herbs by HPLC-DAD and LC-MS/MS. J Liquid Chromatog Related Technol, 2017, 40: 640-648

21 Rashid J, Ahsan F. A highly sensitive LC-MS/MS method for concurrent determination of sildenafil and rosiglitazone in rat plasma. J Pharm Biomed Anal, 2016, 129: 21-27

22 Hasnain MS, Ansari SA, Rao S, et al. QbD-driven development and validation of liquid chromatography tandem mass spectrometric method for the quantitation of sildenafil in human plasma. J Chromatog Sci, 2017, 55: 587-594

23 Ge W, Suryoprabowo S, Xu L, et al. Rapid detection of penbutolol in pig urine using an immunochromatographic test strip. Food Agric Immunol, 2018, 29: 1126-1136

24 Hao K, Suryoprabowo S, Song S, et al. Rapid detection of zearalenone and its metabolite in corn flour with the immunochromatographic test strip. Food Agric Immunol, 2018, 29: 498-510

25 Liu L, Xu L, Suryoprabowo S, et al. Development of an immunochromatographic test strip for the detection of ochratoxin A in red wine. Food Agric Immunol, 2018, 29: 434-444

26 Song S, Suryoprabowo S, Liu L, et al. Development of monoclonal antibody-based colloidal gold immunochromatographic assay for analysis of halofuginone in milk. Food Agric Immunol, 2019, 30: $112-122$

27 Song Y, Wang YY, Zhang Y, et al. Development of enzyme-linked immunosorbent assay for rapid determination of sildenafil in adulterated functional foods. Food Agric Immunol, 2012, 23: 338351

28 Shen X, Liu L, Xu L, et al. Rapid detection of praziquantel using monoclonal antibody-based ic-ELISA and immunochromatographic strips. Food Agric Immunol, 2019, 30: 913-923

29 Kong D, Liu L, Song S, et al. A gold nanoparticle-based semiquantitative and quantitative ultrasensitive paper sensor for the detection of twenty mycotoxins. Nanoscale, 2016, 8: 5245-5253

30 Isanga J, Mukunzi D, Chen Y, et al. Development of a monoclonal antibody assay and a lateral flow strip test for the detection of paromomycin residues in food matrices. Food Agric Immunol, 2017, 28: 355-373

31 Gong X, Liu Y, Xiang H, et al. Membraneless reproducible $\mathrm{MoS}_{2}$ field-effect transistor biosensor for high sensitive and selective detection of FGF21. Sci China Mater, 2019, 62: 1479-1487

32 Jiang W, Zeng L, Liu L, et al. Immunochromatographic strip for rapid detection of phenylethanolamine A. Food Agric Immunol, 
2018, 29: 182-192

33 Xu Y, Wang $\mathrm{H}$, Chen B, et al. Emerging barcode particles for multiplex bioassays. Sci China Mater, 2019, 62: 289-324

34 Huang $\mathrm{P}, \mathrm{Tu} \mathrm{D}, \mathrm{Zheng} \mathrm{W}$, et al. Inorganic lanthanide nanoprobes for background-free luminescent bioassays. Sci China Mater, 2015, 58: 156-177

35 Wang W, Liu L, Song S, et al. Gold nanoparticle-based strip sensor for multiple detection of twelve Salmonella strains with a genusspecific lipopolysaccharide antibody. Sci China Mater, 2016, 59: 665-674

36 Guo L, Xu L, Song S, et al. Development of an immunochromatographic strip for the rapid detection of maduramicin in chicken and egg samples. Food Agric Immunol, 2018, 29: 458-469

37 Guo J, Liu W, Lan X, et al. Development and evaluation of an immunochromatographic strip for rapid screening of sildenafiltype compounds as illegal additives in functional foods. Food Additives Contams-Part A, 2016, 33: 1095-1104

Acknowledgements This work was financially supported by the National Key R\&D Program of China (2016YFD0401101 and KYCX18_1756).

Author contributions $\mathrm{Xu} \mathrm{C}$ and Kuang $\mathrm{H}$ designed the experiments. Suryoprabowo $\mathrm{S}$ and Liu L performed the experiments. Cui $\mathrm{G}$ and Kuang $\mathrm{H}$ participated in data analysis. Xu C drafted the manuscript, and all authors read and approved the manuscript prior to submission.

Conflict of interest The authors declare that they have no conflict of interest.

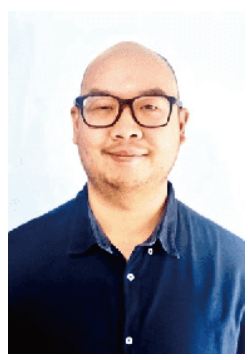

Steven Suryoprabowo is a $\mathrm{PhD}$ candidate under the supervision of Prof. Chuanlai $\mathrm{Xu}$ at Jiangnan University. His research interests focus on developing rapid and sensitive methods to determine analytes using immunochromatography strip test.

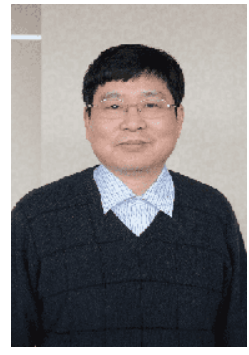

Chuanlai Xu is the Director of International Lab of Biointerface \& Biodetection, Jiangnan University. Leader of the Food Safety Innovation Team in Priority Areas Accredited by the Ministry of Science and Technology, Fellow of the Royal Society of Chemistry. He worked as a visiting scholar at the University of East Anglia, UK in 2007 and University of Michigan in 2008, respectively. His research interests include: (1) self-assembly of advanced inorganic materials and optical properties discovery; (2) fabrication of nano-devices and their applications in biotechnology. He combines nanotechnology and biological recognition to promote the real application of novel biosensors. He has been authorized more than 210 Chinese or international patents and realized commercialization of more than 500 monoclonal antibodies. He has published more than 350 scientific papers, 3 invited book chapters and 3 books. He was awarded four times for the 2nd National Science and Technology Progress Award (2007, 2009, 2011, and 2017) and Special Allowance of Chinese State Council. He serves as an Editor in Chief, Food Agricultural Immunology, and Editorial Boards of Science China Materials, Critical Reviews in Analytical Chemistry, Current Nanoscience, etc.

\section{胶体金免疫层析分析方法用于同时检出减肥茶和 咖啡中西布曲明和西地那非}

Steven Suryoprabowo ${ }^{1,2}$, 刘丽强 ${ }^{1,2}$, 匡华 ${ }^{1,2}$, 崔钢 ${ }^{3}$, 胥传来 ${ }^{1,2 *}$

摘要 本文建立了一种方便、快速、高特异性的胶体金免疫层析 检测方法, 用于同时检测减肥茶和咖啡中的西布曲明(SB)和西地那 非(SID). 我们首先制备了胶体金纳米粒子(CG), 然后使之与单抗结 合形成CG-mAb，将CG-mAb与抗原分别喷涂到基板上形成结合垫 和检测条带, 其中所需的抗原和抗体均由本实验室制备. 经过条件 优化, 该方法在PBS缓冲溶液 $\left(0.01 \mathrm{~mol} \mathrm{~L}^{-1}, \mathrm{pH} 7.4\right)$, 以及三种减肥 茶和三种咖啡样本中，对SB和SID的消线值均为 $500 \mathrm{ng} \mathrm{mL}^{-1}$; 检测 时间仅需 $5 \mathrm{~min}$. 该方法对减肥茶和咖啡样本中SB和SID的快速检 出具有实际应用价值. 